\title{
Commentary: Size and margin do matter, but is it the whole story?
}

\author{
Paul A. J. Beckers, MD, Lawek Berzenji, MD, and Paul E. Van Schil, MD, PhD
}

\footnotetext{
From the Department of Thoracic and Vascular Surgery, Antwerp University Hospital and Antwerp University, Antwerp, Belgium.

Disclosures: Authors have nothing to disclose with regard to commercial support.

Received for publication Nov 3, 2018; accepted for publication Nov 5, 2018; available ahead of print Dec 13, 2018.

Address for reprints: Paul E. Van Schil, MD, PhD, Department of Thoracic and Vascular Surgery, Antwerp University Hospital, Wilrijkstraat 10, B-2650 Edegem (Antwerp), Belgium (E-mail: paul.van.schil@uza.be).

J Thorac Cardiovasc Surg 2019;157:1658-9

$0022-5223 / \$ 36.00$

Copyright $(2) 2018$ by The American Association for Thoracic Surgery

https://doi.org/10.1016/j.jtcvs.2018.11.036
}

Resection of lung metastases is a hotly debated topic at major oncological and thoracic surgical conferences. The main question remains whether surgical resection significantly improves survival. Is the reported survival in surgical series due to interference with the oncological process or solely due to selection bias? At the present time, no randomized evidence is available, and results of the PulmiCC trial are awaited for. ${ }^{1}$ The largest available retrospective series included more than 5000 patients and was published in 1997. ${ }^{2}$ Factors proven to be significant were macroscopic complete resection, number of metastases, with a single metastasis having the best survival, and finally, diseasefree interval with a better prognosis for patients with a disease-free interval longer than 3 years.

Because these metastases are blood borne in contrast to bronchogenic carcinoma, several techniques were developed to remove these lesions with sparing of as much lung parenchyma as possible. ${ }^{3}$ Although these different techniques, ranging from clamping and suturing to laser ablation, have been well described, a safe margin around these lesions has not been determined (Figure 1). In the present series of 335 patients undergoing 679 wedge resections for colorectal lung metastases, the 5-year risk of local recurrence was $20.6 \%$. Two factors emerged from this study: A longer margin length decreased the risk of local recurrence, and a larger tumor size increased this risk. A pathologic margin length of at least half the tumor size was found to be safe with a local recurrence rate of less than $11 \%$. The findings of the authors are certainly useful for daily surgical practice. However, the question remains whether size and margin are the only relevant factors. Can their conclusions also be expanded to other tumor types?

It should be mentioned that not all lung nodules observed on imaging techniques are similar, and several histologic types may coexist. We recently reported a patient with a history of colon cancer and 5 lung nodules with 4 different histologic types on final pathologic examination. ${ }^{5}$ In the

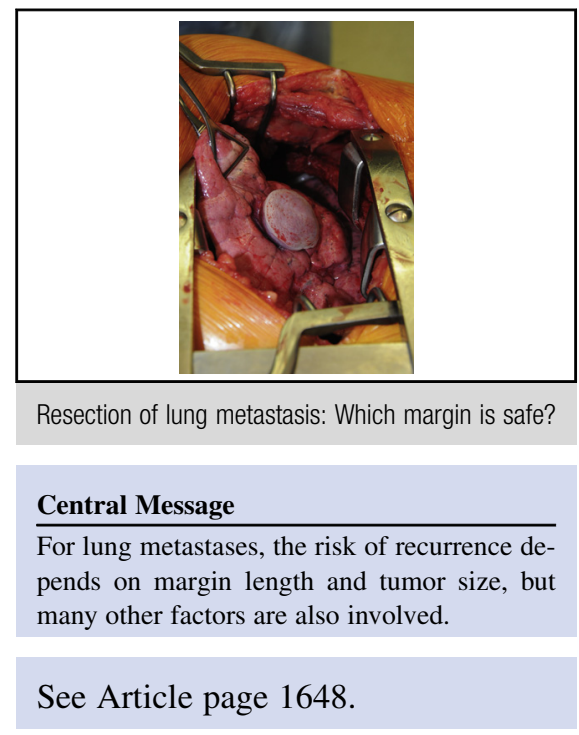

present series, all lesions were removed by staplers, and most probably, the results can be extrapolated to the other described techniques of local extirpation.

Biology of the primary tumor and its resulting metastases are also important factors to be considered. As already shown by Pastorino and colleagues, ${ }^{2}$ melanoma metastases have a high tendency of intrathoracic and extrathoracic recurrences resulting in a poor prognosis. Although the authors tried to incorporate biological factors in the present article, these proved not to be significant. ${ }^{4}$ Equally, the time of occurrence is relevant: Synchronous metastases usually have a poorer prognosis than metachronous lesions occurring years later.

As mentioned before, patients with a single metastasis have the best prognosis, probably because of a lower metastatic burden. In the 8th TNM classification for lung cancer, the M1b category was redefined as a single metastasis in a single distant organ with an intermediate prognosis between the unchanged M1 a subcategory and M1c disease, currently defined as multiple lesions in 1 or more distant organs. ${ }^{6}$ The category M1b corresponds to the concept of oligometastatic disease, which recently has gained much interest, although "oligo" literally means a few and not a single one. So, it seems that there is an intermediate category with limited metastatic disease for whom combined systemic and local ablative therapy may improve overall prognosis, as shown in the recent randomized phase II trial of Gomez and colleagues. $^{7}$ 


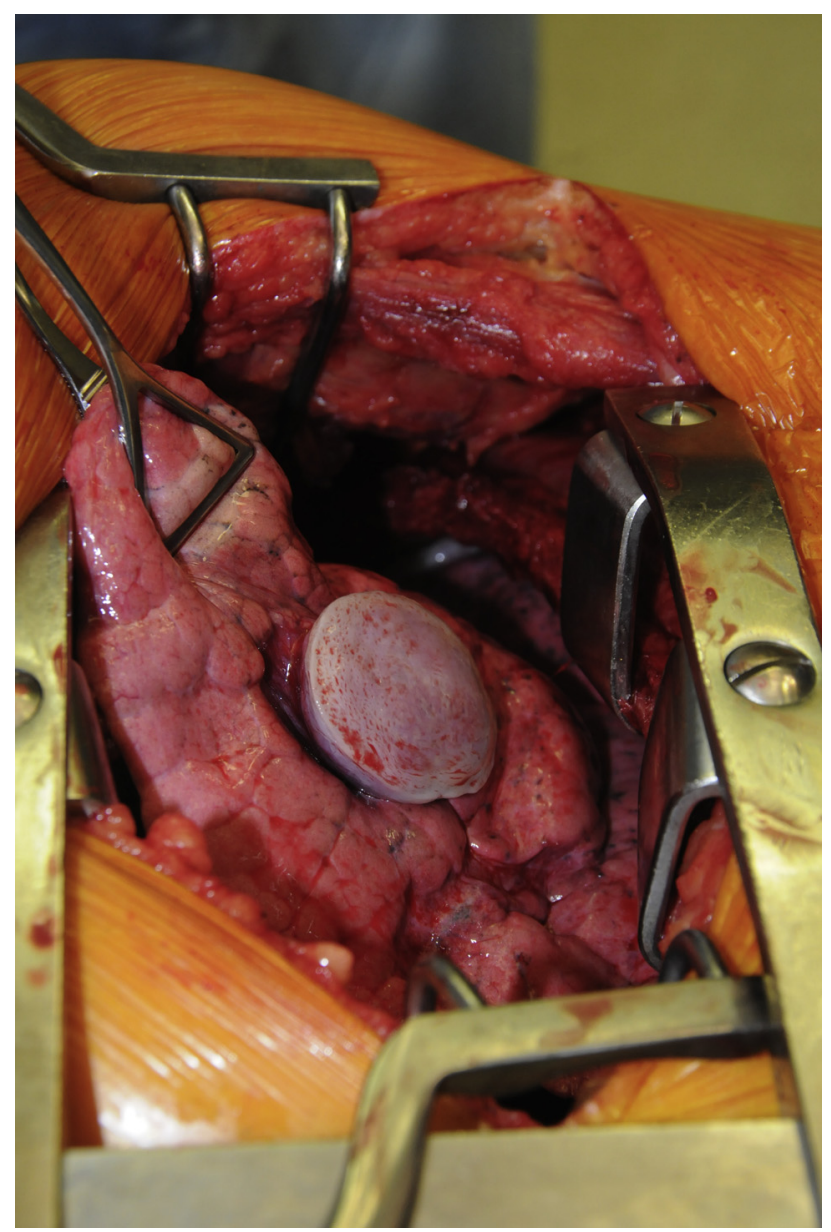

FIGURE 1. Resection of lung metastasis: Which margin is safe?

Although the concept of oligometastatic disease was introduced more than 10 years ago, a precise definition is currently not available. This led the European Organisation for Research and Treatment of Cancer to create a specific task force addressing synchronous metastases. After an extensive survey and a consensus conference, a maximum of 5 metastases in no more than 3 organs was proposed at the 19th World Conference on Lung Cancer in Toronto in September 2018 (abstracts MA25.01-03). Hopefully, this will give to a more uniform reporting of patients with a limited burden of metastatic disease.

Pulmonary metastatic disease will remain a hot topic in the near future, and the present article is certainly a timely addition showing that the risk of recurrence is low when a margin length of half the tumor size is obtained. ${ }^{4}$

\section{References}

1. Migliore M, Milošević M, Lees B, Treasure T, Di Maria G. Finding the evidence for pulmonary metastasectomy in colorectal cancer: the PulMicc trial. Future Oncol. 2015;11(2 Suppl):15-8.

2. Pastorino U, Buyse M, Friedel G. The International Registry of Lung Metastases Long-term results of lung metastasectomy: prognostic analyses based on 5206 cases. J Thorac Cardiovasc Surg. 1997;113:37-49.

3. Van Schil PEY, den Hengst WA, Allen MS, Putnam JB Jr. Pulmonary metastases. Chapter 108. In: LoCicero J III, Feins RH, Colson YL, Rocco G, eds. Shields' General Thoracic Surgery. 8th ed. Philadelphia: Wolters Kluwer; 2019:1383-412.

4. Nelson DB, Tayob N, Mitchell KG, Correa AM, Hofstetter WL, Sepesi B, et al Surgical margins and risk of local recurrence after wedge resection of colorectal pulmonary metastases. J Thorac Cardiovasc Surg. 2019;157:1648-55.

5. Toelen C, De Maeyer M, Van Schil P. Five lung nodules, four different pathologic findings: not all lung lesions are the same. Acta Chir Belg. 2016;116: 388-9.

6. Eberhardt WE, Mitchell A, Crowley J, Kondo H, Kim YT, Turrisi A III, et al. The IASLC Lung Cancer Staging Project: Proposals for the revision of the M descriptors in the forthcoming eighth edition of the TNM classification of lung cancer. $J$ Thorac Oncol. 2015;10:1515-22.

7. Gomez DR, Blumenschein GR Jr, Lee JJ, Hernandez M, Ye R, Camidge DR, et al Local consolidative therapy versus maintenance therapy or observation for patients with oligometastatic non-small-cell lung cancer without progression after first-line systemic therapy: a multicentre, randomised, controlled, phase 2 study. Lancet Oncol. 2016;17:1672-82. 